\title{
EUROSON 2012
}

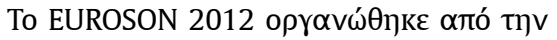

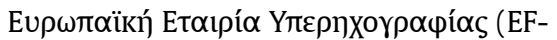

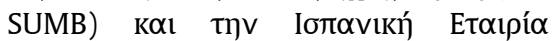

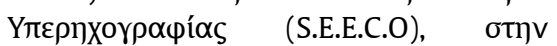
M $\alpha \delta$ pítᄁ, oтo Palacio Municipal de Con-

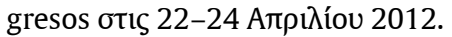

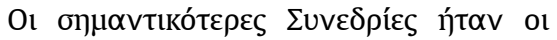

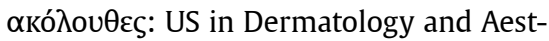
hetic Medicine, Advances in Musculoskeletal US, Liver Elastography, The cutting edge of musculoskeletal US for rheumatic diseases, Clinical US in the Field of the Primary Medicine, US and liver transplant, Echography update in breast and gynecological disease, Update in prenatal-neonatal and pediatric gastrointestinal US, Ultrasonography and fetal therapy, Advanced indications of US in Sports Injury, Role of US in Pancreatic Pathology, Non Liver CEUS Session, Shockwave treatment, Early Stage Hepatocellular Carcinoma, Latest advances in Doppler echocardiography, Vascular US, US in Anesthesia, US in the management of chronic intestinal inflammation disease, Echo-Doppler in the Management of Vascular access, Endoanal and Endorectal US and US in Emergency Medicine.

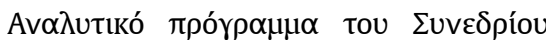

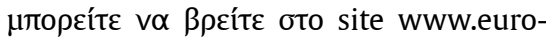
son2012.com.

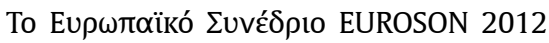

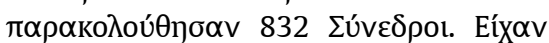

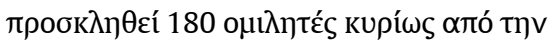

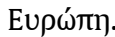

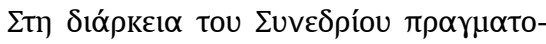

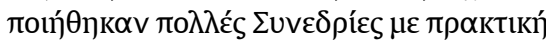

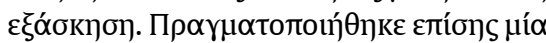

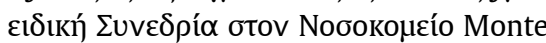

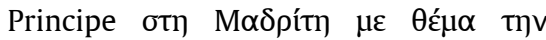

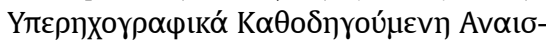
$\theta$ noía (US guided blocks in anesthesia:

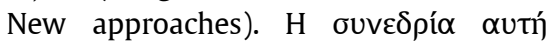

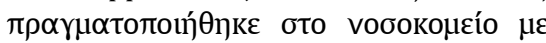

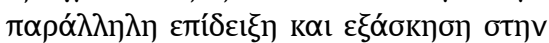

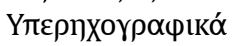

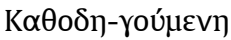

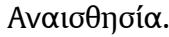

\section{Board of Directors meeting} $\nabla$

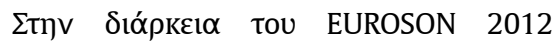

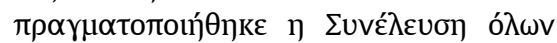

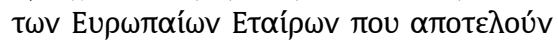

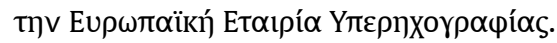

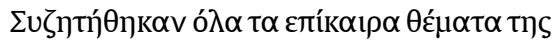

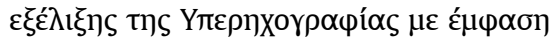

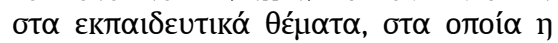

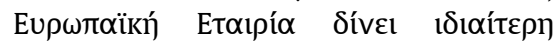

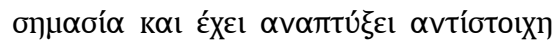

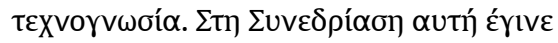

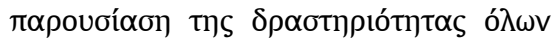

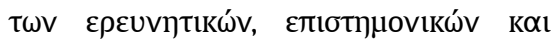

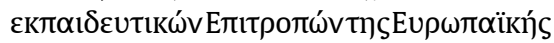

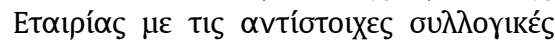
$\alpha \pi о \varphi \alpha ́ \sigma \varepsilon ı \zeta$.

\section{Ultraschall in der Medizin / Euro- pean Journal of Ultrasound (EJU) $\checkmark$}

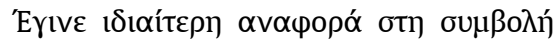

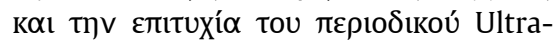
schall in der Medizin / European Journal of

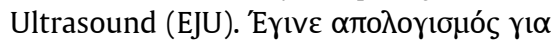

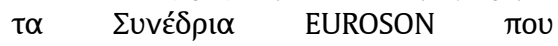

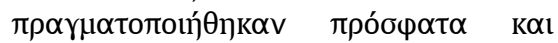

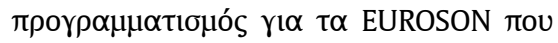

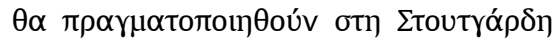

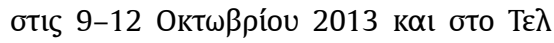

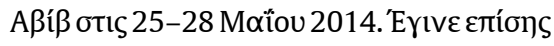

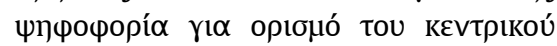

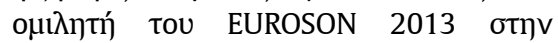

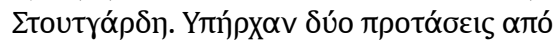

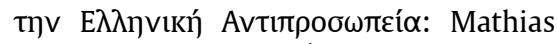

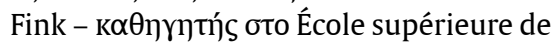
physique et de chimie industrielles oтo

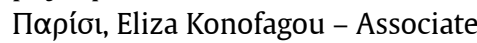

Professor of Biomedical Engineering and Radiology, Columbia University, New York

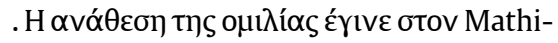
as Fink.

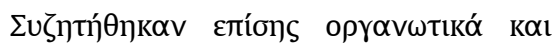

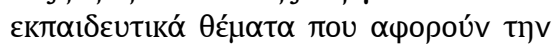
opүóv

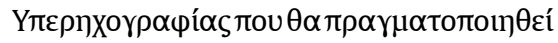

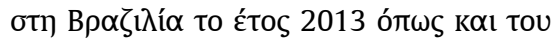

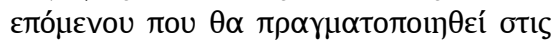
НПА то ह́тоऽ 2015.

\section{EUROSON 2015 in Athens $\nabla$}

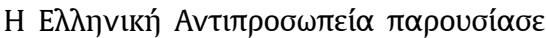

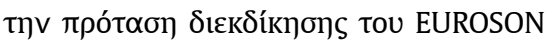

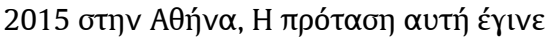

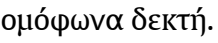

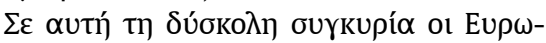

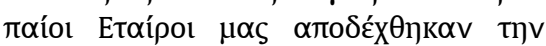

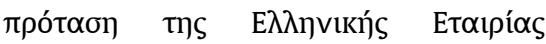

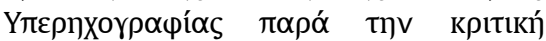

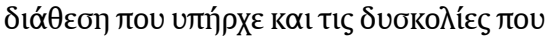

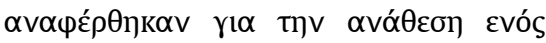

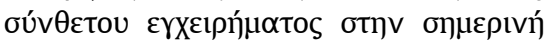
овкоvоники́ бuүкupía.

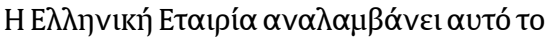

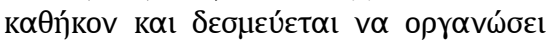

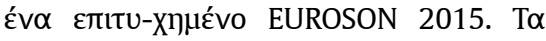

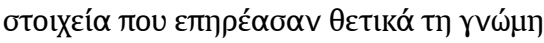

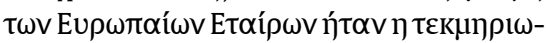

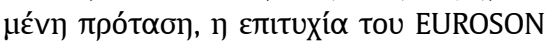

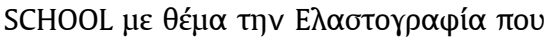

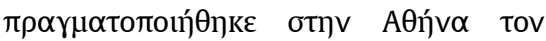

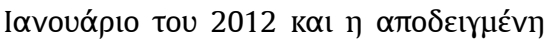

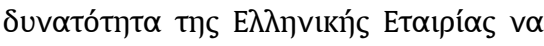

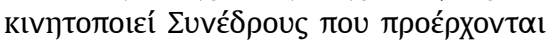

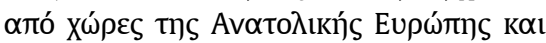

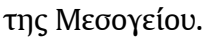

\section{EFSUMB Course Book On Ultrasound $\nabla$}

Edited by Christoph F. Dietrich H

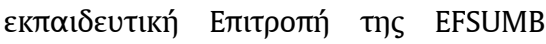

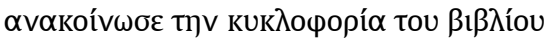
«EFSUMB COURSE BOOK ON ULTRA-

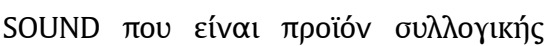

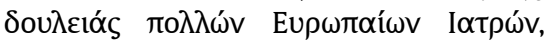

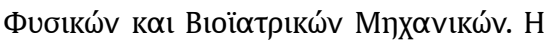

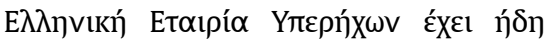

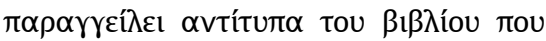

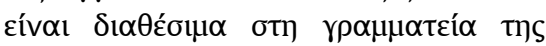

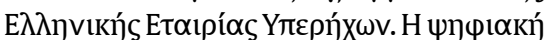

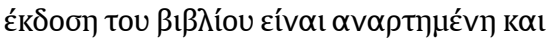

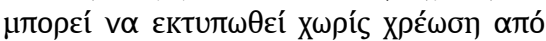

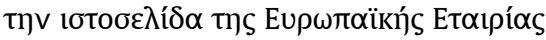

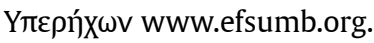

